\title{
TUDO É INVENÇÃO, MAS QUASE TUDO ESTÁ ACONTECENDO: \\ B. KUCINSKI E ANOVA ORDEM
}

Thaís Sant'Anna Marcondes ${ }^{1}$

\begin{abstract}
Resumo
Este trabalho pretende analisar a ficção política de B. Kucinski, A Nova Ordem, e discutir de que forma ela se constitui como alegoria do Brasil atual, marcado por forças opressoras do passado ditatorial. Discutiremos de que modo esta distopia funciona como um aviso ao leitor sobre as tendências autoritárias da presente política brasileira, que ameaça a liberdade da população e se mantém no poder através do controle de informações.
\end{abstract}

\section{Palavras-chave}

Kucinski. Distopia. Autoritarismo.

\section{1) Introdução}

Em tempos de intensa difusão de fake news, correntes de desinformação ganham força nas redes sociais, alertando para o número crescente de brasileiros que ainda desconfiam da ciência. Soma-se a isso a política vigente que enfraquece e ataca o conhecimento científico, disseminando a ignorância. As universidades públicas do país veem suas verbas serem cortadas dia após dia, com a justificativa de que nesses lugares supostamente o que se pratica é a balbúrdia. O apoio financeiro dado aos pesquisadores foi reduzido a quase nada. O resultado desse panorama é que, cada vez mais, as pessoas levam a sério dados provenientes de fontes duvidosas; além disso, as pesquisas acadêmicas que visam à evolução científica estão sendo vistas como desnecessárias, e o que é pior, aquilo que já estava provado há mais de 500 anos, como a forma do planeta, vem sendo motivo de dúvida. A nova ordem do Brasil é a apologia à ignorância.

$\mathrm{Na}$ contramão desse movimento, a arte ainda resiste. E, se o cenário político é sombrio, o artista escancara as atitudes inacreditáveis de nossos representantes na tela, no livro, no palco, nas ruas. Ainda que a cultura seja comparada ao pum produzido com talco espirrando do traseiro do palhaço ${ }^{2}$, nossos artistas chegam até à cerimônia do Oscar com um documentário que aponta o caminho percorrido pela nação brasileira até

\footnotetext{
${ }^{1}$ Doutoranda em Literatura Comparada pela UFF. Mestre em Teoria Literária e Literatura Brasileira pela UFF.

${ }^{2}$ Comparação feita por Regina Duarte em seu discurso de posse na Secretaria Especial da Cultura.
} 
sua polarização ${ }^{3}$, e outros ganham o Festival de Cannes, de Sydney, de Munique, de Lima ${ }^{4}$.

No âmbito literário, vale destacar a produção do autor brasileiro B. Kucinski, que, aos 70 anos, afastou-se de sua carreira jornalística e ingressou no mundo das letras em 2011 publicando seu romance de estreia, K. Relato de uma busca, que trata do desaparecimento de uma professora de química em meio ao regime militar no Brasil. A omissão, por parte dos militares, de documentos importantes; o silenciamento das vítimas de práticas de tortura; os desaparecimentos sem explicação; a impunidade dos que cometeram crimes terríveis e outros tantos fatores justificam o fato de esse momento histórico ser considerado um "mal de Alzheimer nacional" (KUCINSKI, 2014, p. 12) pelo escritor.

Orwell, em seu livro atemporal 1984, tratava de uma sociedade que transformava as informações históricas em poder para transmitir fatos de acordo com a determinada conveniência do partido. Uma mentira poderia ser imposta como história à sociedade se todos os canais controlados pelo partido repetissem a mesma informação. Uma frase marcante nesse contexto é o próprio lema do partido: “quem controla o passado controla o futuro" (ORWELL, 2016, p. 47).Com as devidas ressalvas em relação à sociedade ficcional de Orwell, pode-se compreender que o cenário político brasileiro descrito em parágrafos anteriores tem suas raízes no apagamento de informações relevantes sobre os arquivos da ditadura que contam um pedaço que falta da história do Brasil. Não nos foi permitido passar nosso passado a limpo e hoje vemos a ditadura militar naturalizada com uma forma de governo heroica.

A repercussão do primeiro livro de Kucinski nos permite observar que, mesmo distante alguns anos do final da ditadura, a literatura ainda se coloca como espaço importante e necessário para revisitar traumas a fim de que se possa repensar esse passado tão doloroso e apontar as marcas que esse tempo obscuro deixou para o presente e para o futuro. Prova disto é que, depois do sucesso de seu primeiro romance, Kucinski publicou outros dois livros que apresentam o regime militar no Brasil como tema central, sem que isso constitua uma repetição exaustiva: Você vai voltar pra mime outros contos e Os visitantes. Essas obras abordam questões não apenas literárias, mas

\footnotetext{
${ }^{3}$ Refiro-me ao documentário dirigido por Petra Costa, Democracia em vertigem (2019).

${ }^{4}$ O filme Bacurau (2019), dirigido por Kleber Mendonça Filho e Juliano Dornelles, foi indicado à categoria Palma de Ouro e venceu na categoria Prêmio do Júri no Festival de Cannes. O filme também foi indicado à categoria Melhor Filme no Festival de Sydney e venceu na categoria Melhor Filme no Festival de Munique e no Festival de Lima.
} 
também acerca do aparato repressor usado pelo governo da época, a angústia dos familiares e amigos dos desaparecidos políticos, e das consequências presentes na atualidade, resultado do desinteresse por essa questão histórica. $\mathrm{O}$ autor trava uma batalha contra a disseminação de uma memória difusa e ambígua sobre essa época; por isso, longe de estar exaurido, esse é um tema que continua a se impor.

As versões oficiais e lacunares dos fatos, o pacto com o silêncio, o controle de informações, a impotência das vítimas e de seus familiares, a opressão das massas e a impunidade dos repressores vão ganhando forma nas obras de Kucinski, vão se metamorfoseando até culminar em novo estágio: um Brasil ficcional caótico, povoado por canalhas e presidido por militares interessados em acabar com o pensamento crítico. Este é o cenário de seu mais recente romance, A Nova Ordem, publicado em 2019, que, sem ceder ao panfletarismo, debate os rumos de um país profundamente marcado pela tendência ao autoritarismo que se repete desde o período colonial em nossa sociedade e nos vínculos com o poder.

Com este livro, B. Kucinski se afasta do golpe militar de 1964, mas trabalha em sua produção literária o retorno do autoritarismo no país em 2019, através da instauração de um governo marcado pelo anti-intelectualismo e presidido por militares, que valorizam o agronegócio e abominam o povo e qualquer tipo de projeto nacional. $\mathrm{O}$ momento histórico da ditadura militar não é mais o tema central da narrativa, como ocorre nos outros livros do autor citados anteriormente, mas a memória sobre esse período retorna para os leitores sob a pena de um escritor interessado em produzir uma ficção política que serve de alerta para a atualidade e para o futuro. Sabe-se que Benjamin promove o Angelus Novus, de Paul Klee, "a um emblema da história vista como sedimentação de ruínas" (ROSENFIELD, 2006, p. 197); assim também é a imagem da história do Brasil no último livro de Kucinski: não há salvação, progresso nem o triunfo da sociedade brasileira após os anos de retomada da democracia pósditadura; o escritor aponta o horror, a maldade, a sedimentação de ruínas que formou a estrutura do país. Na Nova Ordem, os inimigos do governo - os livros, as universidades, os professores, os utopistas - , caracterizados pelo senso crítico, pela intelectualidade, foram exterminados. O romance é uma distopia que ficcionaliza o presente do Brasil, traçando semelhanças com o passado ditatorial que nunca foi passado a limpo direito. A narrativa é fruto de uma observação astuta do autor sobre nossa cultura do esquecimento, que pode gerar, como consequência, o retorno de um passado cruel e violento que não foi expurgado. 


\section{2) O Brasil caótico da nova ordem}

De acordo com Hilário, "o gênero da distopia em particular, emerge como dispositivo de análise radical da sociedade, cujo objetivo é analisar os efeitos de barbárie que se manifestam em determinado tecido social" (HILÁRIO, 2013, p. 201). O livro de Kucinski faz uma previsão assombrosa para nossa sociedade ao acentuar a tendência autoritária dos governos brasileiros que ameaçam a liberdade, problematizando assim danos prováveis, caso as forças opressoras progridam.

Uma frase presente no romance de estreia de B. Kucinski, K. Relato de uma busca, e que reaparece em Os visitantes, é o aviso intrigante no início da narrativa: "Caro leitor: Tudo neste livro é invenção, mas quase tudo aconteceu." (KUCINSKI, 2011, p.8) O aviso dá o tom que conduzirá os livros: ficção e eventos reais se mesclam. A Nova Ordem não vem precedida de aviso do autor, mas a narrativa se encarrega de alertar seus leitores: Tudo neste livro é invenção, mas quase tudo está acontecendo ou pode acontecer em breve. É uma obra que, a exemplo de outros romances distópicos, compreende-se "enquanto aviso de incêndio, o qual, como todo recurso de emergência, busca chamar a atenção para que o acontecimento perigoso seja controlado, e seus efeitos, embora já em curso, sejam inibidos" (HILÁRIO, 2013, p. 202). A narrativa de Kucinski é compreendida enquanto aviso com relação à sociedade brasileira atual, pois a analisa através da narrativa da experiência de sujeitos que assistem sem reagir à ascensão de um governo autoritário.

A Nova Ordem apresenta o Brasil como o país da promessa e da falha. A ditadura militar instaurada em 1964 teve fim, mas o processo de redemocratização do país traz a marca da decepção. Se os outros livros do autor reuniam testemunhos de traumas pessoais que iam se tecendo até formarem uma ficção que toca na memória coletiva que havia sido dilacerada junto com os torturados, A Nova Ordem apresenta esse trauma como motivo de renovação para o sistema repressivo: o passado ditatorial que resiste à elaboração dessa memória do mal retorna atualizado nos dias de hoje.

No primeiro capítulo, em um vasto galpão abandonado, estão diversos cientistas - todos homens - que foram pegos pelos militares e reunidos ali. Os relatos das prisões são inusitados: um estava no motel, outro estava operando um paraquedista etc. Muitos desses intelectuais são caracterizados pela vaidade, pois, apesar do desconforto, estavam animados; afinal o que parecia uni-los ali era uma lista em que constava os nomes dos mais importantes cientistas do país. Alguns relatam que estavam 
pesquisando assuntos importantes e necessários quando foram surpreendidos pelos militares, como a desnutrição em crianças quilombolas e a primeira vacina nacional contra a dengue. Outros não estão presentes porque se autoexilaram.

O capítulo é polifônico e, em uma das inúmeras conversas que estão tendo, alguém analisa aquela situação do galpão cheio de pensadores presos por militares e rememora uma novela de Nathan Englander ${ }^{5}$ que satiriza o fuzilamento de escritores na URSS por ordens de Stalin. Na novela, os personagens também relatam as formas inusitadas através das quais foram capturados, construindo um tecido narrativo divertido e surreal, já que todos sabem que em poucos momentos serão fuzilados e parecem não se importar com isso. Outro cientista, ao ouvir os comentários do colega, se mostra aliviado por saber que no Brasil de 2019 não há nenhum psicopata como Stalin que ameaçava o pensamento crítico porque era hostil ao seu modo de governar. E é neste episódio que a narrativa nos apresenta o governo em atividade no momento:

- Com Stalin ou sem Stalin eles podem fazer o que bem entenderem [...]. Podem até nos fuzilar.

- Impossível! Protesta outro jurista, presidente da OAB.

- Na Nova Ordem tudo é possível, retruca o catedrático.

- Mas isso é fascismo!

- Chame como quiser, eu digo que vivemos um estado excitado do capitalismo que se manifesta sempre que é preciso refrear os avanços do povo. (KUCINSKI, 2019, p. 15)

Sabe-se que o golpe de 64 foi uma reação ao movimento de reformas ${ }^{6}$ que eram defendidas por setores progressistas da sociedade brasileira e que significavam um avanço para a população mais carente. Os militares criaram o fantasma do comunismo para legitimar seu regime de exceção a partir da política do medo aos comunistas. Assim como em 1964, quando os setores mais conservadores da sociedade sentiram-se ameaçados pelas reformas do governo Jango que pretendiam reduzir as desigualdades sociais, no contexto da narrativa, o Brasil de 2019 também precisa refrear os avanços do povo, como o cientista afirmara. E, dessa forma, reavivando o trauma coletivo que foi a ditadura militar no país, a Nova Ordem põe fim às universidades federais e fuzila todos os professores titulares reunidos naquele galpão, liquidando os principais formuladores do pensamento crítico no país.

\footnotetext{
${ }^{5} \mathrm{O}$ episódio a que o personagem faz referência é um conto do autor americano intitulado "O vigésimo sétimo homem”, que conta sobre a perseguição de Stalin aos escritores judeus que escrevem em iídiche.

${ }^{6}$ As Reformas de Base, um programa estruturado pelo governo de João Goulart, estipulavam a reforma agrária, tributária, eleitoral, bancária, urbana e educacional.
} 
A explicação para o fim das universidades federais é dada em nota de rodapé, como tantas outras explicações no livro, sendo referida por um édito que esclarece as exigências da Nova Ordem. Esses numerosos éditos nos apresentam o panorama caótico da sociedade brasileira: privatização de empresas estatais, autarquias e bancos; extinção do INSS; idade mínima de 80 anos para aposentadoria; fim do Bolsa Família e de benefícios sociais ao idoso pobre e ao deficiente físico; substituição das disciplinas de sociologia, política, psicologia, literatura, história, geografia, antropologia e línguas estrangeiras (exceto o hebraico) pelas de educação moral e cívica, criacionismo e estudos bíblicos; imposição da censura; fim do Sistema Único de Saúde; entre muitos outros. Os éditos do livro nos remetem aos atos institucionais que ocorreram durante o regime militar. Eram decretos que feriam a constituição vigente, mas que os militares afirmavam serem necessários para que se pusesse fim à corrupção e ao avanço do comunismo no país. De forma semelhante, os éditos da Nova Ordem ferem as leis vigentes em prol da manutenção de um governo perverso.

Entretanto, o que mais assusta não é somente a familiaridade que os éditos inseridos no livro apresentam com os atos institucionais da ditadura militar, mas as referências claras que são feitas ao atual governo do país. A Nova Ordem extingue o ministério da Indústria e do Comércio, o ministério do Trabalho e Emprego, o ministério dos Direitos Humanos, a FUNAI, a Secretaria de Economia Solidária, entre outros. Além disso, o governo acaba com todas as universidades federais do país e todos os cientistas são mortos metralhados por militares. Traçando um paralelo com o Brasil não ficcional, podemos nos deparar com uma infinidade de semelhanças. Uma das primeiras medidas tomadas pelo governo Bolsonaro foi a redução do número de ministérios para enxugar a máquina pública, dentre eles estão alguns que a Nova Ordem da ficção de Kucinski também extinguia ${ }^{7}$. A Secretaria de Economia Solidária foi transformada em departamento do ministério da Cidadania ${ }^{8}$. O ministério da Agricultura ficou responsável pela identificação, delimitação e demarcação de terras indígenas, tarefa que agora não cabe mais à FUNAI ${ }^{9}$. O ministério dos Direitos Humanos passou a se chamar ministério da Mulher, da Família e dos Direitos Humanos e retirou a

\footnotetext{
${ }^{7}$ Disponível em: https://www12.senado.leg.br/noticias/materias/2019/01/02/medida-provisoria-confirmaestrutura-de-governo-de-jair-bolsonaro

8 Disponível em: http://mds.gov.br/area-de-imprensa/noticias/2019/fevereiro/com-nova-secretariaministerio-da-cidadania-projeta-acoes-na-area-de-inclusao-produtiva

${ }^{9}$ Disponível em: https://brasil.elpais.com/brasil/2018/12/28/politica/1546015511_662269.html
} 
comunidade LGBT de suas diretrizes ${ }^{10}$. A universidade pública não acabou, mas passou a ser vista como inimiga do povo, lugar de balbúrdia, que vem sofrendo uma asfixia financeira ${ }^{11}$. Em entrevista à TV $247^{12}$, o autor falou sobre as referências que faz ao governo Bolsonaro no romance. De acordo com Kucinski, a tentativa de construir uma distopia que fosse alegoria do Brasil atual faria com que o leitor, apesar de ser capaz de reconhecer que a narrativa é irreal, compreendesse as semelhanças com o que é real, para dar mais relevo a coisas que pode não estar percebendo na atualidade.

Na ficção, somos apresentados a um importante personagem, Angelino, um exengenheiro que possui problemas com a bebida e atualmente cata livros na rua para ganhar dinheiro. Por conta de um decreto da Nova Ordem, todos eram obrigados a jogar todos os livros que possuíam fora. Catar todos esses livros para levar ao depósito de lixo faz Angelino rememorar seu trauma pessoal: a faculdade, os saraus na casa do tio, as leituras com as irmãs, toda a sua vida anterior ao problema com a bebida, os bons momentos voltam. "Sente-se tão aviltado quanto os livros, ele próprio atirado ao lixo. A simbologia é forte demais. Dói." (KUCISNKI, 2019, p. 24).

Ademais, outro personagem que aparece nesse capítulo é o Zacarias, dono do depósito para onde Angelino leva os livros. Zacarias é uma figura que nos remete aos informantes do governo. O édito 4/2019 determina que zeladores, porteiros, vigilantes de quarteirão, capatazes e chefes de turno devem reportar atitudes suspeitas e situações atípicas à Agência Nacional de Vigilância Social (ANVISO).Na Nova Ordem, todo objeto estranho que chega ao depósito, Zacarias dá parte à ANVISO, fato que faz Angelino não confiar mais nele para mostrar um santinho da Utopia que encontrou. Os utopistas são um grupo de resistência que renega a violência, luta pela extinção dos bancos que, através do édito $3 / 2019$, obriga as pessoas a se endividarem. O santinho que Angelino encontra traz a seguinte exortação em letras miúdas:

\footnotetext{
O reino da Igualdade está chegando

A nova ordem tem seus dias contados

Deus não criou a Terra para alguns

Deus criou a Terra para todos

Os bancos têm parte com o maligno

Afasta-te dos bancos
}

\footnotetext{
10 Disponível em: https://oglobo.globo.com/sociedade/medida-provisoria-assinada-por-bolsonaro-naoexplicita-diretrizes-para-populacao-lgbti-23341254

${ }^{11}$ Disponível em: https://brasil.elpais.com/brasil/2019/05/02/politica/1556819618 348570.html

12 Entrevista dada à TV 247 pelo autor B. Kucinski em junho de 2019. Disponível em https://www.brasil247.com/cultura/bernardo-kucinski-bolsonaro-supera-qualquer-possibilidade-daimaginacao-humana-d1dafetn
} 
Afasta-te da nova ordem

Fecha tua conta bancária

Liberta-te da dívida

Livra-te dos teus cartões de banco

Nenhum homem pode ser escravo de outro homem (KUCINSKI, 2019, p. 32)

A mensagem abala Angelino, que enfia o santinho no bolso e cata o livro Utopia, encontrado entre os outros livros que o ex-engenheiro levou para o depósito de lixo. O livro é um romance filosófico de 1516 do autor inglês Thomas More, que descreve uma ilha imaginária governada pela razão, ambiente idealizado que contrastava com o contexto político europeu da época. Os utopistas da Nova Ordem adotavam uma postura contrária à organização política daquela sociedade e buscavam uma sociedade idealizada: democrática, livre, sem bancos, nem exploração trabalhista, onde predominaria a igualdade entre os homens. Por esta razão, os utopistas são os inimigos do Estado e os militares buscarão seu extermínio.

Outro personagem importante para a presente análise é Ariovaldo. Ele é um militar que vive em meio a alguns traumas: a mudança de patente graças a um gabarito que o tenente Fernandes providenciou para ele, seu casamento falido e o acompanhamento das sessões de tortura dos utopistas. Como ocorria nos porões da ditadura, há um médico que observa as torturas para não deixar o preso morrer até contar tudo o que sabe; em A Nova Ordem Ariovaldo é responsável por esse trabalho, que considera um trabalho qualquer, muito semelhante ao que Hannah Arendt relatou em Eichmann em Jerusalém (1999). A filósofa, ao observar o julgamento de Eichmann - um dos responsáveis pela Solução Final, que matou milhares de judeus — afirma que o homem repetia enfaticamente ser inocente no sentido da acusação, já que ele não se via responsável pela morte desses judeus, pois apenas obedecia ordens, seguia as leis e o Estado; se as diretrizes apontavam para o extermínio dos judeus a qualquer custo, assim ele fazia. A exemplo de Eichmann, Ariovaldo apenas segue ordens administrativas que julga, inclusive, serem boas: "Ele apenas cumpre sua missão, que de certo modo é até humanitária. Impedir que aquilo vire um matadouro. Tentar dar racionalidade ao processo de extração de informação.” (KUCINSKI, 2019, p. 38)

Entretanto, o trabalho que Ariovaldo cumpre deixa nele algumas marcas. O personagem é inserido no livro através da narração de um pesadelo em que é torturado em um interrogatório onde buscam saber quem foi que deu o gabarito da prova que o 
promoveu. Ariovaldo tem consciência de que o pesadelo foi provocado por ter assistido a uma sessão de tortura de uma freira que não contou nada. Mas essa memória do mal que voltou para que ele revivesse o sofrimento em sonho é interpretada da pior forma possível:

Seu pensamento volta ao pesadelo. Todo sonho é uma charada. Lembra-se do rumor da véspera. O Estado Maior está montando a lista de promoções. Foi pela promoção que ele colou na prova. Deve ser essa a mensagem; se no sonho ele revela a artimanha que lhe deu o primeiro lugar na prova, uma nova artimanha poderia lhe dar o primeiro lugar na lista de promoções. (KUCINSKI, 2019, pp. 38-39)

E, desta forma, Ariovaldo desperta para uma grandiosa ideia que será o motor central dos acontecimentos narrados no livro: se ele próprio revelou em sonho seu maior segredo e delatou o amigo, induzir os presos a sonharem seria útil para capturar o conteúdo dos sonhos e ter acesso a todas as informações que a tortura não é capaz de acessar. Dessa forma, menos dor seria infligida aos presos e não haveria limites para descobrir tudo o que se quisesse sem a interferência da resistência deles.

A esposa de Ariovaldo, Marilda, é irmã do ex-engenheiro Angelino, e há a sugestão de que supostamente também seja irmã da freira que estão torturando. Marilda, que parece não resistir a fardas, mantém um relacionamento extraconjugal com o general Lindoso Fagundes, e será esse o motor inicial da próxima promoção de seu marido. A aparência do general com quem Marilda vai se relacionar confirma a influência sofrida pela Nova Ordem de figuras como Stalin e Pinochet, pois nos remete a um símbolo: o bigode.

[...] o General Lindoso Fagundes acompanha satisfeito a movimentação, confiando seu espesso bigode, cultivado ao estilo dos seus dois ídolos, o general Augusto Pinochet e o marechal Josef Stalin. Para Lindoso, cada um a seu modo exerceu o poder supremo, o de ditar quem pode viver e quem deve morrer. (KUCINSKI, 2019, p. 63)

Stalin e Pinochet influenciam o pensamento dos governantes da Nova Ordem, como é o caso do general Lindoso Fagundes. Além disso, o capítulo que trata da admiração excessiva dos militares brasileiros por Stalin e Pinochet também traz semelhanças com o que foi vivido durante os anos de chumbo no Brasil. Uma delas é a teoria do inimigo interno. Em 1964, houve a criação do Serviço Nacional de Informações (SNI) que, na teoria, buscava a coleta, a análise e a difusão de informações sobre questões de segurança nacional, e que, na prática, era um centro de poder que agia 
por conta própria na luta contra o inimigo interno (FAUSTO, 2015, p. 259), isto é, contra aqueles que se opunham ao regime. De acordo com Duarte-Plon, a doutrina francesa serviu de alicerce ao edifício teórico que elaborou a tese do inimigo interno, que deveria ser exterminado, e redesenhou a Doutrina de Segurança Nacional. Segundo essa teoria, "o adversário a ser combatido é o inimigo interno, representado por comunistas, intelectuais, operários, camponeses, líderes sindicais, estudantes e artistas, simpatizantes de ideias consideradas subversivas." (DUARTE-PLON, 2016, p. 37). Assim como no regime militar do passado, na Nova Ordem, a luta era novamente contra o inimigo interno, que ameaçava a segurança nacional, porque doutrinava contra o sistema e contra os bancos, mobilizava as massas através de mensagens de esperança como a do santinho e convocava para a luta armada. Identificar os utopistas não foi tão fácil, pois, diferentemente dos blackblocs que quebravam bancos mascarados e vestidos de preto, eles eram pessoas comuns, indistinguíveis, que não praticavam a violência. Era um grupo composto por estudantes, artistas e intelectuais. Para identificá-los, a exemplo do SNI e adaptando-se ao contexto tecnológico de 2019, as Forças Armadas buscavam os subversivos cruzando os nomes dos que recusaram empréstimo bancário com matrículas escolares e contas de luz e de água e rastreando palavras-chave trocadas pelo WhatsApp.

Outra semelhança marcante com o período ditatorial consiste nos métodos para dar fim aos corpos. Como se sabe, muitos foram os desaparecidos pelo regime militar sobre os quais até hoje não se tem informação. A irmã e o cunhado do autor foram alguns desses casos. De forma semelhante, a Nova Ordem também objetivava dar fim aos presos por questões de segurança. E, para isso, os responsáveis, influenciados por “instruções recebidas dos chilenos nos idos gloriosos" (KUCINSKI, 2019, p. 66), traçaram um plano cuja finalidade era anestesiar as pessoas, amarrar um lastro em cada uma delas e jogar ao mar.

Para cada especificidade de grupo de utopistas, há um plano detalhado cruel, discreto e inteligente para exterminá-los. Porém, o que mais chama a atenção é quando a narrativa trata da ausência de informações, descrita quando o general Fagundes fala sobre a Operação Capela, que visava ao fim dos padres subversivos, como foi feito com os gays, sem nenhum registro da operação, nada por escrito, tudo verbal. Da mesma forma como ocorreu no Brasil durante o golpe militar, o sumiço de informações ainda é uma característica de momentos em que cruéis atrocidades acontecem. 
Em 1993, os militares informaram ao Ministério da Justiça o que constava em seus arquivos sobre os desaparecidos políticos. A ausência de informações realmente importantes era notória nos relatórios. Quando foram questionados sobre a escassez de informações, alegaram que

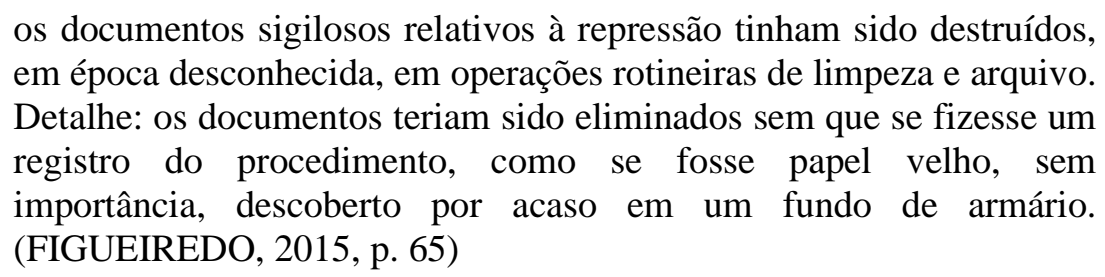

Em 2013, uma equipe de jornalistas e historiadores foi montada para pesquisar a estrutura de informação e repressão política construída pelo regime ditatorial. Uma das pesquisas revelou um conjunto de documentos sigilosos e mostrou que as Forças Armadas ainda conservam seu próprio acervo do período militar, mantendo em segredo fatos que os militares ainda não estão dispostos a assumir.

O que a ficção política de Kucinski vem salientar é que, se a sociedade se conforma pacificamente e aceita o silêncio imposto sobre as vítimas que desapareceram durante a ditadura militar, fica instituído que a omissão ou a ausência de provas físicas de atos bárbaros é algo normal e que não gera consequências futuras. Isto é, novamente retomando o lema do partido da ficção de Orwell, quem controla as informações detém o poder, é capaz de manipular a história e, por conseguinte, controla o futuro. A distopia de Kucinski aponta no futuro próximo as evoluções opressivas das tendências do passado brasileiro que ainda se mantém no presente.

Outro episódio que nos remete às mentiras divulgadas sobre os desaparecimentos da época da ditadura militar é quando a freira, que provocou o pesadelo em Ariovaldo, morre, pois ele não estava durante a tortura quando aconteceu uma hemorragia. Resta a ele fazer o atestado de óbito para que, se um dia a família insistir muito em saber, não seja culpa da tortura a morte da desaparecida. É travada aqui uma guerra psicológica entre o Estado e a família que busca seus desaparecidos, através da transformação da informação verdadeira em mentira forçada; é a manipulação do presente:

Só lhe resta produzir o atestado de óbito. Mera precaução, pois será dado sumiço ao corpo. Freira de clausura, ainda bem. [...] O senão é o de sempre, a família. Cedo ou tarde saberão do sumiço. A família é sempre um problema. Se um dia questionarem, ou descobrirem que foi aqui, será dito que ela se atirou do terceiro andar. Preenche: Maria 
Aparecida da Paixão de Cristo, traumatismo craniano. (KUCINSKI, 2019, p. 75)

Assim também acontece em um momento posterior no enredo, quando o general Fagundes revela a Ariovaldo o novo segredo da Nova Ordem, que eles chamarão de "Ação solidária". Com o discurso de implantar campos de reeducação e trabalho longe das cidades para mendigos, prostitutas, drogados, aleijados, cegos, doentes mentais, portadores de síndrome de Down etc., eliminarão todas essas pessoas no mar, conduzindo o país por uma eliminação do excesso de gente, por um saneamento demográfico. Esse discurso nos remete a traumas como os campos de concentração nazistas e as mentiras disseminadas pelo governo ditatorial no Brasil.

Outro personagem interessante da narrativa é o Messias, que pensou em ser padre quando pequeno, mas cresceu e acabou tendo como função denunciar padres utopistas para a Nova Ordem. Ele descobre se os padres são alinhados com os utopistas, contata o delegado e a este fica incumbido plantar olheiros na missa, avaliar os sermões e investigar se a igreja abriga forasteiros e se mantém curso de alfabetização de adultos. Mas há um trauma em Messias que não passa. Ele não consegue esquecer que entregou um dominicano garoto ainda e, por consequência, conseguiram pegar uma madre: "O rosto redondo e rosado do dominicano de Bofete não sai da cabeça." (KUCINSKI, 2019, p. 101) "Merda de missão especial. Não fosse o relatório dele, o dominicano não seria preso e não pegavam a madre.” (KUCINSKI, 2019, p. 104) Quando pensa na mãe, católica fervorosa que muito se orgulhava da filha que virara freira, acha que ela não ia gostar do que ele faz. De tanto sofrer com esse trauma, em uma de suas missões, ao invés de fazer o que havia planejado durante a confissão, acaba falando tudo para o padre, rememora os eventos dolorosos de seu ofício como delator e acaba se libertando; pois, no dia seguinte a esse ocorrido, não volta a fazer o que deveria para o governo, mas foge.

Nos últimos capítulos, Angelino, influenciado pelo santinho dos utopistas e pela leitura do livro Utopia, estranha o sumiço dos outros moradores de rua e guarda consigo um revólver que encontra enquanto estava revirando os lixos. A arma lhe dá uma sensação de poder. O personagem é a representação do desamparo. Este afeto político, segundo Safatle (2018, p. 54) pode reduzir as demandas de cuidado por figuras protopaternas de autoridade soberana e nos abrir para sermos sujeitos que buscam rupturas. A Nova Ordem expõe a tomada de consciência de Angelino, que reconhece sua vulnerabilidade e se constitui no final do romance como um sujeito político com força 
de transformação atirando contra o general Lindoso Fagundes, pois, de acordo com o pensamento de Safatle, "só pessoas desamparadas são capazes de agir politicamente" (ibid., p. 50). Se lembrarmos, por exemplo, de um personagem marcante da literatura de Lima Barreto, poderíamos pensar que a Policarpo Quaresma é reservado um triste fim porque o personagem confiava e tinha esperanças no poder vigente que o dominou e o submeteu. Quando Quaresma resolve fazer algo pelas injustiças que viu e vivenciou, ele escreve uma carta para o Marechal Floriano Peixoto, expressando assim uma demanda de cuidado pela figura de autoridade. Por não ter buscado uma ruptura efetiva, o destino de Quaresma é marcado pela melancolia que o paralisa, enquanto que o desamparo sentido por Angelino, no livro de B. Kucinski, abre caminho para a tomada de atitude e o transforma em sujeito político ativo que é capaz de combater a figura de autoridade.

Por fim, o livro de B. Kucinskis e encerra com o projeto de Ariovaldo de captação de informações através do sono entrando em colapso, pois foram tantos os testes e experimentos em busca de aperfeiçoar a técnica que, sem desejos e paixões, as pessoas tinham parado de sonhar. Esse grande projeto foi também seu grande trauma, pois o militar se internou em crise depressiva e sofre de alucinações seguidas de surtos de hiperatividade em que escreve por várias horas seguidas sobre o que sonhou, revivendo suas memórias do passado traumático através do sono para tentar encontrar os motivos do colapso.

\section{3) Considerações finais}

Procuramos, no presente artigo, analisar a ficção política de B. Kucinski, A Nova Ordem, observando as representações do autoritarismo que perpassam as relações políticas, econômicas, sociais e humanas no passado e no presente do Brasil. O autor, em obras anteriores, trava uma batalha contra o apagamento proposital da memória da ditadura militar. No caso de A Nova Ordem, o que está em jogo é uma sociedade que não expurgou seu passado sombrio, foi conivente em manter trancado nos porões da ditadura o horror disseminado nessa época, e atualmente vê ressurgir um governo autoritário naturalizado e tomado como heroico.

O autor afasta-se dos anos de chumbo e foca seu olhar na atualidade, intensamente marcada pela opressão e pelos silêncios daquela época. Os anos passaram, o momento da narrativa é 2019, e, enquanto no universo não ficcional as pessoas tomam como verdade incontestável as fake news, na ficção, a distopia de B. Kucinski abre os olhos do leitor para enxergar o Brasil caótico que vem sendo construído pelos 
governantes militares que detêm o poder através do controle de informações e tentam combater a todo custo seus maiores inimigos - o senso crítico, a intelectualidade, a arte, a literatura.

Por fim, a narrativa analisada oferece ao leitor duas vias: uma marcada pela falta de esperança, em que as pessoas param de sonhar, e, assim, não há como sobreviver; e a outra aponta para uma esperança calcada no desamparo de um personagem influenciado pela ideologia utopista que será capaz de agir politicamente e dar fim ao general que comandava as atrocidades cometidas pelos militares na Nova Ordem.

A literatura produzida por B. Kucinski trabalha com imagens ficcionais que apontam para situações parecidas com o mundo real, reforçando as barbaridades não inventadas que a sociedade naturaliza e não percebe: as desigualdades, a violência banalizada, a manipulação, a alienação, a censura, a ascensão do autoritarismo. Sua ficção política traz o presente potencializado e funciona como previsão desencantada de um futuro que pode piorar.

\section{Referências}

ARENDT, Hannah. Eichmmam em Jerusalém: um relato sobre a banalidade do mal. São Paulo: Companhia das Letras, 1999.

DUARTE-PLON, Leneide. A tortura como arma de guerra: Da Argélia ao Brasil Como os militares franceses exportaram os esquadrões da morte e o terrorismo de Estado. Rio de Janeiro: Civilização Brasileira, 2016.

FAUSTO, Boris. História Concisa do Brasil. São Paulo: Editora da Universidade de São Paulo, 2015.

FIGUEIREDO, Lucas. Lugar nenhum: militares e civis na ocultação dos documentos da ditadura. São Paulo: Companhia das Letras, 2015.

HILÁRIO, Leomir. Teoria crítica e literatura: a distopia como ferramenta de análise radical da modernidade. Anuário de Literatura, Florianópolis, v. 18, n. 2, p. 201-215, out. 2013.

KUCINSKI, Bernardo. K. Relato de uma busca. São Paulo: Cosac Naify, 2014.

A nova ordem. São Paulo: Alameda, 2019.

ORWELL, George. 1984. São Paulo: Companhia das letras, 2016.

ROSENFIELD, Kathrin. Broch, Musil, Benjamin: três abordagens da imagem e da história. In: SELIGMANN-SILVA, Márcio (Org.). Palavra e imagem, memória e escritura. Chapecó: Argos, 2006. p. 185-203. 
SAFATLE, Vladimir. O circuito dos afetos: corpos políticos, desamparo e o fim do indivíduo. Belo Horizonte: Autêntica, 2018.

\title{
TODO ES INVENCIÓN, PERO CASI TODO ESTÁ SUCEDIENDO: \\ B. KUCINSKI Y A NOVA ORDEM
}

\begin{abstract}
Resumen
Este artículo pretende analizar la ficción política de B. Kucinski, A Nova Ordem, y como esa se constituye como una alegoría del actual Brasil, marcado por las fuerzas opresoras del pasado dictatorial. Discutiremos como esta distopía funciona como una advertencia para el lector sobre las tendencias autoritarias de la política brasileña actual que amenaza la libertad de la población y permanece en el poder a través del control de la información.
\end{abstract}

\section{Palabras clave}

Kucinski. Distopía. Autoritarismo. 